\title{
CRISIS DEL MANDATO REPRESENTATIVO EN EL ESTADO DE PARTIDOS *
}

\author{
POR \\ ANTONIO TORRES DEL MORAL \\ Profesor agregado de Derecho político \\ Universidad Nacional de Educación a Distancia
}

\begin{abstract}
SUMARIO
1. EL PASO HISTÓRICO DEL MANDATO IMPERATIVO AL REPRESENTATIVO: 1.1. Los becbos. 1.2. Aportaciones tebricas para la construcción del modelo: A) Teoría inglesa del «trust». B) Teoría francesa del mandato representativo. C) Teoría del órgano. D) Teoría de la unidad política ideal del pueblo.2. RAZONES Y SINRAZONES DE LA CONSTRUCCIÓN DEL MODELO.-3. El FUNCIONAMIENTO REAL DEL MODELO EN LA ACTUALIDAD. - 4. LA PRECARIA EXISTENCIA HISTÓRICA DEL MANDATO REPRESENTATIVO.-5. SUPUESTOS JURÍDiCOCONSTTTUCIONALES: 5.1. La titularidad de los escaños. 5.2. La exigencia de la dimisión sin fecba y otras sanciones que el partido impone al diputado. 5.3. Abandono del partido por parte del diputado. 5.4. Escisión del partido. 5.5. Disolución de un partido por declaración de su inconstitucionalidad.6. ¿CABE LA REVOCACIÓN EN EL ACTUAL MODELO DE REPRESENTACIÓN?: 6.1. El mandato imperativo en el constitucionalismo soviético. 6.2. Articulación técnica y posición de los partidos.
\end{abstract}

Hace siglo y medio James Mill hacía una alabanza sincera de la representación como fenómeno e institución política del Nuevo Régimen, diciendo de ella que era el gran descubrimiento de los tiempos modernos, que lograba solucionar todas las dificultades de la convivencia política. Más cercano a nosotros, pero en tono igualmente fervoroso, Loewenstein la considera una invención tan importante como la máquina de vapor, la electricidad, el motor de explosión o la fuerza atómica.

Lejos de mi ánimo restarle importancia al modelo de representación que ha llegado a nuestros días. Pero sí parece prudente matizar el énfasis de tales asertos.

* Conferencia pronunciada en agosto de 1981 en el curso que sobre «Problemas actuales de la institución parlamentaria» dirigió el profesor Lucas Verdú en la Universidad Internacional «Menéndez Pelayo», curso que se publicará próximamente. Agradezco a la U. I. M. P. su autorización para la publicación anticipada de este texto. 


\section{EL PASO HISTORICO DEL MANDATO IMPERATIVO AL REPRESENTATIVO}

\subsection{Los bechos}

En una conferencia pronunciada por el profesor Sánchez Agesta hace ya quince años abordaba el problema de la participación en la vida pública a través del proceso representativo distinguiendo con nitidez los conceptos de representación y democracia. La representación, venía a decir, es una importante rectificación de la democracia.

Porque, en efecto, entre el representante y el representado no hay una identidad de voluntades ni de intereses, aunque pueda haber una coherencia y semejanza. Representante y representado son una dualidad y, por consiguiente, puede haber entre ellos una tensión en cuanto el primero no haga valer satisfactoriamente la voluntad o el interés del segundo.

La concepción medieval de la representación trató de superar esta dualidad mediante el cuaderno de instrucciones y la revocabilidad del representante. Modelo este conocido con el nombre de mandato imperativo. Pero la Revolución francesa, como antes había acontecido algo más calladamente en Inglaterra, barrenó este concepto prohibiendo tanto las instrucciones como la revocación y sustituyendo a los representados concretos del modelo anterior por la nación, concepto sublimado en la idealidad de un todo que no se identifica con sus partes y que incluye generaciones pasadas; presentes y futuras. Como dice Carré de Malberg, estamos ante la nación entendida como cuerpo unificado, como universalidad global unitaria e indivisible que no se identifica con los individuos ni con los grupos que existen en ella.

Esta idea de la representación política, este modelọ que nos ha llegado con la denominación de mandato representativo, al operar sobre dicho concepto mítico, emocional, de la nación y de su soberanía (que venía a llenar el hueco que dejaba la soberanía monárquica), acentuó —dice Sánchez Agestala dualidad entre representante y representado.

Que este modelo de representación, en el que el pueblo no tiene posibilidad de gobernar, se aparta de la idea - al menos de la idea originariade democracia es evidente. Rubio Llorente y Nicolás Muñiz lo argumentaban cumplidamente hace ya algunos años en una densa y extensa colaboración en la revista Triunfo, y yo mismo dediqué a este problema mi trabajo sobre «Democracia y representación en los orígenes del Estado constitucional» en 1975.

En realidad, a mi manera de ver, estamos ante uno de esos movimientos históricos de avance-retroceso: lo que se gana hacia la democracia con el paso de la soberanía monárquica a la nacional, se evapora en parte con la radical separación entre gobernante y gobernado. Rousseau lo detectó con agudeza al criticar el sistema representativo inglés, que esclaviza al ciudadano - dicecreándole la ilusión de que es libre.

Pero también hemos de reconocer, en honor a la verdad, que ha sido este sistema político, curiosamente, el que ha evolucionado hasta permitir una mayor, aunque limitada, influencia popular en el poder. Es decir, que el sistema representativo ha ido transformándose en democracia representativa. 


\subsection{Aportaciones teóricas para la construcción del modelo}

Este sistema de representación ha recibido tres aportaciones teóricas principalmente: la teoría inglesa del trust, la francesa del mandato representativo y la alemana del órgano.

\section{A) Teoría inglesa del «trust»}

En Inglaterra, como se sabe, la teoría constitucional se ha ido decantando sobre los hechos. En nuestro caso podemos arrancar de 1583, cuando sir Thomas Smith publica su De Republica Ánglorum. Aquí comienza un proceso que ha conceptuado de modo ejemplar Birch en su obra Gobierno responsable $y$ representativo.

Sucedía que ni los mandantes podían prever todos los giros de las negociaciones de sus representantes ni podían estar reunidos continuamente para hacerles llegar sus instrucciones. Estas instrucciones, por consiguiente, comenzaron a hacerse en términos muy generales, tanto que, como dice Jellinek, un pueblo tan práctico como el inglés debió darse cuenta muy pronto de su inutilidad.

De otro lado, el rey exigía en sus cartas de convocatoria que los representantes llevaran amplios poderes ita quod pro defectu buiusmodo potestatis negotium infectum non remaneat. Esto es, para poder ultimar todos los asuntos y que no quedaran paralizados por falta de poderes de los representantes.

El Agreement of the People, de 1653, daba ya por supuesto que los representantes tenían la suprema confianza (trust) en orden al cuidado del conjunto. La misma idea reproduce Locke al argumentar que los pactantes originarios de la sociedad instituyen un poder legislativo al que confian la defensa de los derechos. En este esquema, las elecciones no son tanto un modo de imponer el pueblo su voluntad cuanto un modo de frenar a los trustees, a los fideicomisarios, a los depositarios del poder. Y Burke, en 1774, escribe a los electores de Bristol argumentándoles que el representante tiene libertad absoluta y no puede quedar ligado por promesas obligatorias. Los diputados representan intereses generales y no están sometidos a mandato. Su relación con los representados es la confianza.

\section{B) Teoria francesa del mandato representativo}

La doctrina francesa del mandato representativo, que es la que ha terminado dándole nombre al modelo, se fragua en vísperas de la Revolución.

Ya Montesquieu, en su inevitable Espíritu de las leyes, XI, 6, habla de la libertad de los representantes y de la pura generalidad de las instrucciones que el pueblo puede darles.

Condorcet, que distingue entre el representante y el meró comisionado, recomienda también, en 1789 , que se den unas instrucciones muy generales a los representantes. En la Asamblea Constituyente de 1791 aborda de nuevo 
el problema expresándose así: «Es conservando la independencia de mis opiniones... como yo me esforzaré en responder a esta distinción tan honorable de la confianza de mis conciudadanos.» Obsérvese que también Condorcet entiende la relación como de confianza. Y en 1792 le escribe del siguiente tenor a sus electores de l'Aisne: «Mandatario del pueblo como soy, yo haré lo que crea conforme a sus verdaderos intereses; el pueblo me ha enviado no para sostener sus opiniones, sino para exponer las mías... y uno de mis deberes hacia él es la independencia de mis opiniones.» Pero esta independencia, piensa, debe aplicarse no en constituir la voluntad nacional de un modo descomprometido, sino en declararla después de haberla conocido y comprobado.

Sieyès entiende ya la soberanía nacional no como un poder fraccionado individualmente o por distritos, sino como un poder indiviso de la nación como un todo. De ahí deriva el abate la necesaria independencia de los representantes y su facultad de expresar la voluntad nacional, sin tantos escrúpulos como veíamos en Condorcet: «De cualquier manera que sean diputados, que se reúnan y que deliberen... su voluntad común valdrá por la de la nación misma.»

$\mathrm{Y}$ los textos legales revolucionarios fueron aún más expresivos, siendo de recordar a este respecto la Declaración de Derechos del Hombre y del Ciudadano, de 1789, la Ley de 22-XII-1789 y la Constitución de 1791, conforme a los cuales textos nuestro problema queda planteado y resưelto en los siguientes términos:

1. La ley es la expresión de la voluntad general.

2. La nación sólo puede querer y actuar por medio de sus representantes, que la representan a ella en su conjunto y no a sus electores concretos.

3. Quedan excluidas las instrucciones y la revocación de los diputados.

4. «La Constitución francesa — dice de sí misma la de 1791- es representativa».

En la raíz de esta concepción está Hobbes, contra lo que pudiera parecer, pues, en efecto, en Hobbes el pactum subiectionis confiere todo el poder al soberano, que no está sometido a ningún vínculo; en realidad se daba una identificación del monarca con el pueblo y con el Estado, los cuales no tenían, según Hobbes, una voluntad distinta de la de aquél. Pues bien: los revolucionarios franceses terminaron haciendo lo mismo, sólo que sustituyendo parcialmente el Rey por el Parlamento, cuya voluntad - la ley-- se identifica con la voluntad general, es la voluntad general; ésta no puede ser otra cosa que la voluntad manifestada por los representantes.

Añadamos tan sólo que lo que en Hobbes se resolvía con bastante lógica, con la lógica monolítica de la coincidencia en un mismo sujeto de la titularidad de la soberanía y el ejercicio del poder, quiebra ahora esa lógica con el principio de la soberanía nacional, que introduce una dualidad de incómoda explicación.

\section{C) Teoría del órgano}

Posteriormente, los cultivadores de la Teoría General del Estado (Jellinek, Gierke, Laband, etc.) elaboraron la doctrina del órgano, que, con variantes, hacen suya Carré de Malberg, Orlando y otros. 
Jellinek niega que haya dualidad entre el representante y el representado arguyendo que hay una sola voluntad, pues la de uno vale por la del otro. El representante es el órgano del representado, del pueblo, que, a su. vez, es órgano del Estado en su función de elegir (esto es: el pueblo, en las elecciones, no expresa su voluntad, sino la del Estado). $Y$ así como una persona jurídica de derecho privado no quiere ni se expresa por sí misma, sino sólo a través de su órgano correspondiente, igualmente el pueblo sólo puede querer: y expresarse a través de sus representantes.

Hauriou se halla cercano de este planteamiento. Para él, los electores son órgano representativo de primer grado de la nación, siéndolo el Parlamento de segundo grado. El órgano de primer grado nombra al de segundo grado, pero nada más; su relación es funcional, pero no le transmite poder ninguno.

Por este camino Carré de Malberg llega incluso a negar el carácter representativo del sistema parlamentario. En la elección hay una designación, y sólo esto. Decir que los diputados representan a la nación significa que no representan a los electores individuales, ni a los colegios electorales, ni a lós grupos particulares, sino a la totalidad global que los incluye. Pero la nación, así entendida, es el Estado. Propiamente hablando, por tanto, el diputado es representante del.Estado, órgano suyo. Así, pues, el Estado representativo no es tanto un sistema de representación cuanto un sistema de organización de la voluntad nacional.

Y Orlando entiende que el pueblo no transmite el poder al representante, sino que sólo lo selecciona, y éste recibe su poder de la Constitución. Y si el pueblo no transfiere el poder, mal podrá dar instrucciones para su ejercicio.

\section{D) Teoría de la unidad política ideal del pueblo}

Otra construcción interesante acerca de la representación política, que inspira parcialmente a Carré de Malberg pero que se opone abiertamente al modelo que estudiamos, es la que sustenta Carl Schmitt, y que siguen, entre otros, Leibholz y Triepel.

El pueblo, para ellos, no puede ser representado en su unidad natural, pero sí en su unidad política, como existencia espiritual superior. Pero eso es precisamente el Estado: el pueblo entendido como unidad política superior. Luego los representantes lo son propiamente del Estado.

En fin, no nos detenemos en esta construcción porque se separa en su finalidad del mismo Estado representativo y de su modelo de mandato, tendiendo a un Estado plebiscitario en el que el principio de la representación -aristocrático- deja paso al principio de identidad, que, según explica Schmitt, es el democrático. Max Weber, en Economía y sociedad, dice que en esta concepción el representante pasa de ser servidor del pueblo a ser señor suyo, y que en el Estado plebiscitario llega a ser sólo servidor del jefe del partido. 


\section{RAZONES $\dot{Y}$ SINRAZONES DE LA CONSTRUCCION DEL MODELO}

Cada vez va siendo más generalmente aceptado por la doctrina que el mandato representativo advino históricamente en unos supuestos sociológicos bastante precisos, muy distintos de los actuales.

En efecto, la prohibición de instrucciones y de revocación tenía su razón de ser en un sistema de sufragio restringido y de colegio uninominal, donde era inevitable el contacto personal entre un pequeño grupo de electores y el diputado. En estas condiciones, el peligro de presiones localistas es muy grande. $Y$ en los días de la Revolución, la prohibición de mandato estaba pensada principalmente para independizar al diputado de las exigencias de los notables locales (que eran, presumiblemente, de la nobleza y del alto clero, esto es, de los estamentos privilegiados) y para lograr así un Parlamento fuerte frente a dichos estamentos y frente al Rey. Y la carta de Burke a sus electores de Bristol adquiere todo su innovador significado en su contexto histórico, como réplica a la proliferación en Gran Bretaña de asociaciones políticas cuyo objeto era precisamente conectar con los parlamentarios $y$, por lo menos, hacerles llegar sus criterios.

Y una vez asentado el Estado constitucional y representativo, seguía teniendo sentido la prohibición de instrucciones durante la vigencia del sufragio censitario por casi las mismas razones: la existencia de un electorado muy reducido y muy poderoso en cada circunscripción.

Pero que tenga sentido histórico no significa que su construcción jurídica fuera correcta. Veámoslo:

a) La teoría de la prohibición del mandato imperativo asentada en el principio de soberanía nacional una e indivisible no es convincente, como se desprende de un doble orden de consideraciones.

De una parte resulta claro que la unidad de poder nó reclama necesariamente ni el monismo de su ejercicio ni la unidad del acto de selección de sus titulares. Si fuera necesario el monismo de su ejercicio, no habría sido lícita la división de poderes, precisamente la tesis más querida de los introductores del Nuevo Régimen. Y si fuera precisa la unidad en el acto de selección de los representantes (que al fin y al cabo es un acto de poder), no cabría más forma electoral legítima que con un colegio nacional único. Y si, como ha sucedido y sucede, el ejercicio de la soberanía admite diversidad de actos y de actores, no se ve por qué va a rechazar las particulares visiones que éstos pudieran aportar al ejercicio del poder.

Pero, por otra parte, es claro que históricamente habían convivido la unidad de la soberanía y las instrucciones y revocación. Y ello aconteció no sólo cuando el Parlamento únicamente presentaba peticiones al Rey, sino incluso cuando aprobaba impuestos, cuando ejercía poder. Nunca se consideró que ello menoscabara la unidad de la soberanía. No se ve la escondida razón de que antes una corporación o una ciudad pudiera instruir y revocar sin menoscabo de la soberanía, y ahora esa misma ciudad no pueda hacerlo porque afecta a la soberanía de ese ente etéreo e impalpable, indeterminado e indeterminable 
que es la nación tal como se la concibió entonces. Como tampoco la descentralización política o el federalismo suponen una fragmentación de la soberanía nacional, a pesar de que tanto una región autónoma como un Estado federado hacen algo más que instruir a un diputado: deciden, legislan. $\mathrm{Y}$ como a nadie se le ocurre sostener que las instrucciones vinculantes que, en nuestros días, dan los gobiernos de los países alemanes a sus representantes en el Bundesrat comporten una ruptura de la unidad de la soberanía. Los ejemplos podrían multiplicarse con un mismo resultado: la doctrina que comentamos es histórica y actualmente insostenible, desde un punto de vista rigurosamente teórico. De manera que no puede sorprendernos en absoluto que en la práctica política se haya mantenido vigente.

b) La teoría del órgano sị que aporta una razón jurídica precisa para la prohibición de las instrucciones; a saber: que el electorado no transfiere el poder, sino que sólo selecciona a su titular; el poder lo confiere la Constitución. Pero, en ese caso, deberá admitirse, exactamente por la misma razón jurídica, que el electorado puede retirar a un diputado de aquella selección, que puede revocarlo, y será la Constitución la que lo prive del poder. Lo mismo que en el proceso de elección, pero a la inversa. Es decir: que, si no las instrucciones, al menos la revocación sí encaja jurídicamente en el modelo de representación que estudiamos. Suponer que la elección es irreversible, irrevocable, es introducir un nuevo elemento en el esquema institucional que no viene exigido ni por su lógica ni por las previsibles necesidades funcionales, ni venía reclamado por los instauradores del Nuevo Régimen en un principio. Así, por ejemplo, Condorcet adujo en diversas ocasiones que la Asamblea sólo cumple una función legislativa que el pueblo le delega sin abdicarla y que puede revocarle mediante expresa declaración.

Pero así se hizo, finalmente, prohibiéndose tanto las instrucciones como la revocación, con lo que se consumó una total inversión de los principios políticos con los que emergió el Nuevo Régimen. Pues, efectivamente, en el Estado constitucional y representativo:

1. No es que exista una voluntad general y la ley intente expresarla, sino que la ley la expresa diga lo que diga, porque la voluntad general no preexiste a la actuación de los representantes.

2. No es que el cuerpo electoral cree una representación para el ejercicio del poder, sino que, en realidad, el cuerpo electoral, en cuanto que es un órgano estatal que cumple una función, es creación de la ley, es decir, de los representantes.

\section{EL FUNCIONAMIENTO REAL DEL MODELO EN LA ACTUALIDAD}

Viniendo ya al funcionamiento del modelo en nuestros días, es lógico que tuviera que adaptarse, andando el tiempo, a la sociedad urbana e industrial, a la extensión del sufragio y a la creación de las grandes organizaciones políticas que encauzan la democracia de masas, entre las que son los partidos políticos los que reclaman nuestra atención en este momento porque han terminado por 
imprimir una honda transformación en el modelo de representación que estamos analizando.

En realidad es discutible si en esa evolución han sido los partidos los que han modificado el sistema parlamentario o ha sido el sistema parlamentario el que ha transformado a los partidos; o si, en tercer lugar, y esto parece lo más probable, la transformación ha sido recíproca. Hoy, dice Andrea Manzella, los partidos y el Parlamento forman la dual estructura política del pueblo en continua y mutua referencia, de manera que no es posible entender la una sin la otra.

Con el sufragio universal, al haber miles o millones de electores por circunscripción, parece inevitable que la representación se haga a través de organizaciones. Los partidos, dice Sartori, reducen a dimensiones manejables cifras que no lo son. Pero el hecho de casi monopolizar el proceso representativo lleva a los partidos a una posición de preeminencia funcional incluso sobre los órganos constitucionales del poder. Puede decirse, parafraseando a Hermann Finer, que el partido es verdaderamente rey de la situación y de la dinámica política. Y no olvidemos que Gramsci vio con agudeza en el partido la encarnación actual del príncipe de Maquiavelo.

Estamos, insiste Sartori, ante un proceso cortado en dos: de una parte, la relación entre los electores y el partido; de otra, la existente entre el partido y los representantes. El problema está en que la cooptación que el partido hace de los candidatos tiende a ser una elección real que mediatiza la que después hace el cuerpo electoral, máxime si tenemos en cuenta que los programas políticos se confeccionan de forma acusadamente centralizada.

Ante la presencia de unos partidos rígida y poderosamente organizados, el representante tiende a ser más el portavoz del partido que de cualquier otra instancia (incluyendo a sus propios electores); y sus vinculaciones partidistas tienden a ser más fuertes que cualesquiera otras (incluyendo las de su clase social). De manera que, según ha señalado Duverger, de los dos mandatos que recibe el representante moderno, el del partido y el del electorado, el segundo prevalece sobre el primero.

En las relaciones entre el partido y los representantes parlamentarios pueden distinguirse dos vertientes: las relaciones individuales entre los dirigentes del partido y los parlamentarios, y el problema específico de la disciplina de voto:

a) En cuanto a las primeras, hoy se observa un cierto predominio del dirigente partidista, aunque no es infrecuente la interpenetración de ambos cuadros y una acumulación de los dos cargos en las mismas personas.

En general, puede decirse que los sistemas electorales proporcionales, con listas cerradas y bloqueadas, potencian la posición de los dirigentes del partido, que confeccionan las listas. El sistema mayoritario atenúa algo esa preponderancia, y más si es con escrutinio uninominal; pero no sucede así en los países bipartidistas, en los que el parlamentario no tiene otra opción que someterse al partido.

b) $\mathrm{Y}$ en cuanto a la disciplina de voto, de la que ya me he ocupado en otro trabajo, diremos ahora tan sólo que:

1. Como dice Duverger, se da dicha disciplina cuando se ha pasado de 
una concepción individualista a otra comunitaria de la representación, en la que los electores se identifican no con un candidato, sino con un partido.

2. A este respecto, los partidos pueden ser elásticos, como los norteamericanos, o rígidos, como los de la izquierda europea (pero también son rígidos el Partido Conservador británico, la Democracia Cristiana italiana y la UCD española, al menos hasta su crisis de 1981). Menos claro está, sin embargo, que esta distinción coincida, como quiere el profesor de París, con la de partidos de cuadros y de masas.

Hoy apenas quedan partidos elásticos. La evolución hacia la rigidez data de hace ya varias décadas. Pérez Serrano hablaba, cuarenta años atrás, de la tiranía ejercida sobre los parlamentarios, que se han convertido en un simple número que incluso vota contra su conciencia. Y B. Crick, con el suave escepticismo político británico, decía: «Se reconoce, ciertamente, que un miembro parlamentario posee una cosa muy vaga llamada conciencia que puede ejercitar no votando en todas las cuestiones relacionadas con el juego, el reclutamiento, el sebo... pero también se reconoce... que un miembro parlamentario no puede tener su conciencia revoloteando en derredor de cualquier problema que surja.»

Estos son los hechos, no tan negativos como se pintan, pero que se imponen con tozudez a pesar de las declaraciones constitucionales en contra. Como dice el mismo Pérez Serrano, «por vía indirecta, aunque con vigor más enérgico, resucita en nuestro tiempo el mandato imperativo, haciendo que los parlamentarios representen no al distrito que los eligió ni a la nación de que son órgano, sino al partido en que militan, que ejerce sobre ellos autoridad castrense severísima».

Kelsen, hace aún más tiempo, postulaba ya en su Esencia y valor de la democracia un sistema democrático que supiera hacer frente a la dictadura de los partidos. $\mathrm{Y}$ en nuestros días la tinta vertida contra la partidocracia es abundante. Crisafulli la critica por su carrera hacia el voto, que la lleva, según dice, a la demagogia y a la corrupción. Zampetti hace lo propio con la correntocracia o, como él la llama, la grupocracia. Y, entre nosotros, un creciente número de publicistas ha escrito sobre el particular en tono progresivamente pesimista.

Pero, por otra parte, no faltan quienes ven en el cada vez más importante papel de los partidos un fenómeno más bien positivo. En 1910 decía Jaurès: «Es preciso librar a los diputados de la servidumbre que les obliga a satisfacer apetitos para conservar mandatos. Es preciso poner más disciplina y moral en el ejercicio del derecho de sufragio; sustituir la competencia entre personas por la lucha entre las ideas; impeler a los partidos a organizarse, a disciplinarse, a presentar a los electores ideas claras en programas precisos...»

Más cercano a nosotrọs, Francesco Leoni cree que la disciplina partidocrática ha introducido algo de orden en la difícil política italiana y que la ausencia de disciplina lleva a los diputados a todas las combinaciones pensables de la alquimia parlamentaria, añadiendo que, por lo común, las críticas a la partidocracia adolecen de una superada concepción individualista de la libertad. Manzella abunda en que las críticas a la partidocracia pecan de un error de 
enfoque: no ven que el Parlamento actual es distinto del decimonónico. En España, lo mismo han escrito Carreras y Vallés en su libro sobre Las elecciones. Para estos autores, la dependencia del parlamentario no sólo no es un mal, sino que debería llegar a ser, a largo plazo, la situación normal del diputado, siempre, claro, que los partidos funcionen de modo verdaderamente democrático; condición esta, sin embargo, que, a mi juicio, ni se da con la suficiente generalidad ni ofrece flancos abiertos y precisos para la seguridad de su cumplimiento futuro, aparte de que su control estatal no deja de ofrecer riesgos notables.

En fin, el problema político por excelencia es hoy ese de la democracia interna de los partidos, resuelto el cual - lo que es harto improbable- los demás se darán por añadidura. Pues, desde luego, nada más deseable que el panorama que pinta Lucio Libertini en su obra ¿Qué Parlamento?, al defender, con buenas razones ciertamente, el actual Estado democrático de partidos. Cuando un diputado comunista acepta la disciplina de voto, dice Libertini, «no se transforma en modo alguno en un pasivo y supino ejecutor, sino que expresa una decisión, en cuya formación ha participado y que se ha madurado en decenas de asambleas, en las discusiones de los órganos colegiales de partido, en el grupo parlamentario y en el grupo de trabajo. Por tanto, tiene la posibilidad de expresar la voz de todos aquellos que lo han elegido y de confrontar con la propia las opiniones ajenas...». Me temo, sin embargo, que haya otros partidos menos democráticos.

\section{LA PRECARIA EXISTENCIA HISTORICA DEL MANDATO REPRESENTATIVO}

Llegados a este punto, en que hemos visto las razones histórico-sociológicas y las sinrazones teórico-jurídicas de la construcción del mandato representativo, así como su funcionamiento real mediatizado por los partidos, cabe que nos preguntemos, parodiando el título de la conocida comedia: Pero chubo alguna vez mandato representativo? ¿Lo hubo en el funcionamiento efectivo del Estado constitucional contemporáneo? ¿En qué proporción y medida?

En una primera aproximación, como la que hemos hecho, se puede inferir que, conforme el sistema fue evolucionando hacia lo que hoy vivimos como democracia representativa, la pureza del principio se iba desvaneciendo y la exquisita independencia del representante iba dejando asomar diversos vínculos. Pero es que, en rigor, se concluye irremediablemente que la independencia absoluta del parlamentario apenas ha existido nunca. Siempre hubo grupos o personalidades de particular prestigio que lograban imponer sus criterios. Antes de que hubiera partidos y grupos parlamentarios, había otros grupos, aunque de menor consistencia; había líderes, notables locales, etc. De manera que el caso de los representantes independientes queda reducido, hoy como ayer, a una hipótesis marginal, casi límite, y más bien ha desempeñado en la Teoría Política el papel de modelo ideal, en el sentido weberiano de la expresión, que, como tal, no se ha realizado nunca en la vida política.

Y si de la historia nos trasladamos a la actualidad, podemos traer a cola- 
ción un buen manojo de prácticas políticas perfectamente conocidas, que sumariamente vamos a recordar:

a) De un lado, los programas han venido a ocupar el lugar de las instrucciones. Naturalmente, la relación jurídica es distinta porque la iniciativa de su redacción y proposición es ahora del representante (de su partido) y el elector no puede modificarlos, como tampoco puede revocar al representante por incumplimiento de ese programa. Pero el hecho ya es buena prueba de que nunca se ha dado una representación pura, una relación del diputado con los electores sin nada de por medio y a solas con su conciencia.

b) En segundo lugar, en la relación representante-partido, ya hemos hablado de la férrea disciplina castrense que la preside.

c) Por otro lado, no hace falta que nos detengamos en exponer las muy variadas relaciones, presiones y vinculaciones entre los grupos de interés y los parlamentarios (aunque no sólo con ellos, claro).

d) En cuarto término, la dependencia en que se encuentra el diputado respecto del partido a la hora de confeccionar las siguientes candidaturas ha venido a sustituir a la revocación de los electores, aunque tampoco aquí deban ocultársenos sus diferencias jurídicas. Es distinto, en efecto, el sujeto que la realiza (el partido) y es diferente el momento de su consumación o perfección (el término de la legislatura); pero, a fin de cuentass, el resultado es muy parecido: la muy probable pérdida del escaño.

e) En quinto lugar se dan, además, algunas prácticas plenamente antijurídicas conforme al sistema representativo formalmente vigente, como son las sanciones al diputado indisciplinado, las dimisiones sin fecha, etc., cuyo análisis dejamos para más adelante. Así, pues, como dice Bobbio, bien puede entenderse la dependencia respecto del partido como el actual «sucedáneo funcional del mandato imperativo».

f) Y, por último, no deja de ser lógico que en estas condiciones los diputados estén volviendo a sus distritos, a cuidar su electorado, a fabricarse una imagen local, a buscar un poco de poder local que le compense su carencia de poder estatal.

A este respecto, Birnbaum, Hanon y Troper ven algo de esquizofrenia, o al menos de incoherencia, en esta situación de los diputados actuales: de un lado, el tirón de sus electores le lleva a adoptar una actuación algo localista; de otro, la máquina del partido le impone una disciplina centralizada.

A mí me parece, sin embargo, que la situación es bien simple y coherente: el partido libera al diputado de las preocupaciones de los grandes problemas nacionales, cargando con ellos una docena de sacrificados dirigentes a cambio de que el diputado vote como se le indique, dado que no conoce los asuntos; $y$, una vez libre el diputado de preocupaciones, es enviado a su distrito a la caza alegre de votos. Todo un detalle.

De este modo está prodigándose bastante en la actualidad la figura del «diputado asistente social», como se le ha llamado con ironía. Es el diputado al que acuden sus electores para resolver o diligenciar una gestión, porque, como dice Alain, todavía un diputado puede hacer temblar a un prefecto y una carta suya abre muchas puertas de la Administración... y además hay que contestarla. Es el diputado que a veces se ve obligado a adoptar posturas ra- 
yanas en la ilegalidad por solidarizarse con una reivindicación local. Es el diputado que ve, como dice André Tardieu, que su diario quehacer local va matando su representación nacional; que ve, según estudios realizados por Claude Escarras, que el 90 por 100 de su correo diario es para problemas locales y personales, en los que se le solicita su intervención cerca de la Administración. En fin, es el diputado común en Francia, donde, según J. E. Medard, en 1958 había un 63 por 100 de los miembros de la Asamblea Nacional que simultaneaban una representación local, cifra que se eleva al 80 por 100 en 1967 y que no parece haber descendido después ostensiblemente, habiéndose invertido, por lo demás, la dirección de esta acumulación de mandatos: antes era el representante local el que aspiraba al escaño parlamentario; ahora es el diputado el que busca el mandato local.

Añadamos, por nuestra cuenta, que no todo es negativo en el referido fenómeno, pues, por uno u otro motivo, el diputado está acercándose de nuevo a su electorado. Sólo que ello sucede añadiéndole una grieta, una más, al nunca demasiado sólido edificio del mandato representativo.

\section{SUPUESTOS JURIDICO-CONSTITUCIONALES}

Hasta aquí, la construcción teórica del mandato representativo y los hechos que lo ponen en cuestión. Pero he anunciado, y ahora me ocupo de ello, que también se suelen dar prácticas en abierta contradicción con el mismo. Y si fácilmente puede colegirse de lo que hasta ahora he expuesto que este modelo de representación no me parece el mejor posible, menos partidario aún soy de las contradicciones jurídicas, con las que las cosas nunca son lo que son ni lo que parecen, pero tampoco lo que no parecen. Estudiaremos sucesivamente:

- El problema de la titularidad de los escaños.

- La exigencia de dimisión sin fecha y otras sanciones que el partido impone al diputado.

- El problema del abandono del partido por parte del diputado.

- El problema que plantea la escisión del partido durante una legislatura.

- La disolución de un partido por declaración de su inconstitucionalidad.

El planteamiento general es bastante nítido: ¿qué valor tienen los preceptos constitucionales que prohíben el mandato imperativo cuando se está dando éste en vías de hecho por parte de los partidos e incluso éstos tienen reconocida jurídicamente su libre actuación en otros preceptos de la misma Constitución.

En Alemania, el artículo 21 de la Ley Fundamental reconoce a los partidos su esencial función de «cooperar a la formación de la voluntad política del pueblo», fórmula esta que nuestra Constitución ha seguido muy de cerca. Se les exige respeto al orden democrático y no comprometer la existencia de la República Federal Alemana, así como democracia interna. Por su parte, el artículo 38 establece el mandato representativo: los parlamentarios representan a todo el pueblo, sin vínculo de mandato, y no están sometidos más que a su conciencia. 
En Italia, el artículo 49 de la Constitución reconoce que los partidos «concurren a determinar la política nacional», y no se les exige más que su actuación conforme al método democrático. $\mathrm{Y}$ el artículo 67 establece la representación nacional sin vínculo de mandato.

En Francia, el artículo 4 de la Constitución reconoce también a los partidos, que, dice, «concurren a la expresión del sufragio», requiriéndoles únicamente el respeto a la democracia y a la soberanía nacional. Y el artículo 27 dice terminantemente: «Todo mandato imperativo es nulo.»

Y en España, el artículo 6 de la Constitución vigente califica a los partidos de instrumentos fundamentales de participación política y les exige estructura y funcionamiento democrático. El artículo 66.2 estatuye la representación nacional y el artículo 67.1 la prohibición de mandato.

Como se ve, los preceptos más precisos en torno a los partidos son el alemán y el español, que habilitan, según creo, el control estatal de la estructura democrática interna de los partidos; así como de su funcionamiento. El precepto francés es el más diluido, pues el respeto a la democracia, al ir inserto junto al respeto a la soberanía nacional, parece exigirlo sólo al régimen democrático constitucional. Y la regulación italiana es ambigua: habla de concurrir a determinar la política nacional con método democrático, lo que abre un abanico demasiado amplio de interpretaciones.

Los enfoques generales en torno al problema que los partidos políticos plantean al mandato representativo varían, naturalmente. Hay autores que, como hacen Radbruch y Hatchek, sostienen que el ordenamiento jurídico no debe intervenir en las relaciones partido-diputado. Otros, como Kollreuter, postulan cambios jurídicos que adecúen la normativa constitucional a la realidad política. No faltan quienes, como Henke, consideran irrelevante el problema; o quienes, como Virga, le dan un enfoque que prescinde del problema de fondo, pues parecen conformarse con que el diputado no vincule jurídicamente su voto aunque se encuentre en una real dependencia respecto del partido.

Veamos, entonces, los supuestos enunciados.

\subsection{La titularidad de los escaños}

En primer lugar, se ha polemizado acerca de la verdadera titularidad de los escaños parlamentarios. Si es cierto - se ha dicho- que los partidos confeccionan las candidaturas y los programas; si es cierto que ponen todo el aparato e infraestructura en la campaña; si es cierto que las elecciones se están personalizando progresivamente en los líderes de los partidos o, al menos, en los posibles equipos de gobierno, siendo los demás elegidos tan sólo el coro que arropa de vez en cuando a los solistas, entonces - se concluye- los escaños, que son ganados por los partidos, deben ser de los partidos.

En España se ha sostenido esta tesis recientemente por parte de algún partido y de un órgano de opinión, que añadía, además, el argumento del sistema electoral proporcional de lista cerrada para el Congreso, encabezada por la sigla y el logotipo del partido. Pero, si así fuera, no podría impedirse que 
el partido cesara a sus diputados a discreción con la excusa de su indisciplina o sencillamente sin excusa. En realidad sobraría la figura del diputado. En las elecciones, los partidos ganarían los escaños en proporción a sus votos, pero sin la estúpida necesidad de confeccionar unas listas e imprimirlas en papeletas; luego, para cada cometido, podía el partido designar a sus miembros más preparados, o simplemente más dóciles, sin la inútil formalidad de cuidarse del lugar que ocupan en la candidatura. Aunque parezca mentira, Birnbaum, Hanon, Troper ven en ello algo así como la panacea para resolver todos los problemas del parlamentarismo: evitaría la falta de preparación técnica de los diputados, produciría movilidad en el equipo de los partidos e incluso evitaría gran parte de las presiones que hoy sienten los diputados por parte de los grupos de interés. (A decir verdad, la idea cuenta, en cierto modo, con el ilustre precedente de Kelsen.) Entonces el Parlamento se compondría sólo de los secretarios generales de los partidos.

No hace falta añadir, sin embargo, que, conforme al derecho constitucional vigente en la Europa Occidental, to es posible tanta belleza. Los partidos intervienen en el proceso electoral activándolo, animándolo, proporcionando candidatos, etc.; pero los candidatos son personas individuales y el Parlamento se compone de diputados, no de grupos, que sólo son asociaciones que dinamizan su funcionamiento. $Y$ es así, como no podía ser menos, incluso en el caso del sistema electoral proporcional.

\subsection{La exigencia de la dimisión sin fecha $y$ otras sanciones que el partido impone al diputado}

En segundo lugar, el examen de las medidas que los partidos suelen adoptar contra sus diputados indisciplinados acaso debiera llevarnos, a su vez, al de las medidas que el Estado podría o debería adoptar contra el partido en cuestión con tal motivo.

Las posiciones divergen de nuevo tanto en el aspecto de las relaciones entre el Estado y los partidos como en cuanto a la prohibición de mandato imperativo.

Para unos (Sica, por ejemplo), el Estado y los partidos son estructuras impenetrables y no pueden injerirse la una en la otra ni viceversa. Esta postura es absolutamente insuficiente porque el Estado no puede abdicar, al menos, del control externo del partido. Hoy día, la postura mayoritaria (Merlin, Predieri, Falcone, Petta...) es la de la exigencia de ese control estatal externo. Pero no faltan los que reclaman incluso un control estatal de la democracia interna del partido: Perticone entiende que el artículo 49 de la Constitución italiana exige democracia interna y externa, puesto que resulta hipócrita o suicida esperar que un partido interiormente autocrático respete los procedimientos democrático-constitucionales; y Crisafulli defiende incluso el control ideológico y programático del partido por parte del Estado.

En cuanto a la prohibición de mandato imperativo, como hemos dicho, las posiciones vuelven a variar. La doctrina más extendida (Longi, Rossano, Manzella, Foderaro, etc.) estima que tal prohibición no afecta a la práctica 
habitual de las instrucciones de voto, pero que garantiza al parlamentario para poder votar como crea conveniente sin que puedan adoptarse medidas contra él en el orden político nacional, esto es, como diputado (aparte de su condición privada de miembro del partido). Kafka, en este mismo sentido, dice que el Estado debe ignorar las prácticas internas del partido y su forma de acordar su comportamiento parlamentario, pero que, por eso mismo, la indisciplina de un diputado es una cuestión interna del partido, que, por tanto, no debe tener consecuencias político-constitucionales (por ejemplo, su cese como diputado). En igual línea se pronunciaba hace ya tiempo Laferrière, según el cual el principio general del estatuto del parlamentario es el de salvaguardar su independencia, como lo prueba el hecho de que ninguna constitución establezca un procedimiento de revocación del diputado por los partidos.

Muy distinto es el enfoque de Lelio Basso, para quien el artículo $67 \mathrm{de} \mathrm{la}$ Constitución italiana (prohibición de mandato) es una simple norma tradicional heredada del Estatuto Albertino, una cláusula de estilo que no tiene otro objeto que afirmar la supremacía de los intereses generales sobre, los loçales y corporativos; debe, por tanto, prevalecer el artículo 49, que constitucionaliza los partidos, por ser una verdadera innovación de la Constitución y, como tal, más expresiva de su espíritu. En términos parecidos se expresa también Paolo Petta.

La conclusión es brillante y refleja un aspecto muy cierto del problema, el que antes denominábamos con Duverger «representación comunitaria». Pero, jurídicamente hablando, dados el sistema representativo todavía vigente y los términos en que está regulado por las constituciones, esta tesis presenta el problema de la discriminación entre preceptos de igual rango y en ocasiones igualmente aprobados por el pueblo en referéndum, además de que lleva al reconocimiento de los partidos como titulares de los escaños, con los inconvenientes - también jurídicos- que antes veíamos.

Por último, una posición ecléctica; que no se pronuncia sobre el problema de los partidos, es la de Savignano y la de Ciaurro, que interpretan la prohibición de mandato como un límite al legislador ordinario, el cual no podrá disponer nada que lleve implícito o explícito el reconocimiento de posibles mandatos imperativos.

A mi parecer, ésta es una consecuencia más de la insuficiencia teóricojurídica y político-práctica del modelo de mandato representativo, que plantea problemas de compatibilidad con la dinámica política real. De manera que acaso conviniera ir acondicionando el modelo, aunque eso suponga un cambio acusado en el parlamentarismo clásico. Pero en tanto se hace, y mientras esté jurídicamente vigente la prohibición de mandato, creo que no se puede, por vía de interpretación, cambiar el contenido de la institución hasta volverlo del revés. Está en juego el ya muy deteriorado valor de la Constitución como norma superior organizadora de la vida política de un país.

Quiero decir, por consiguiente, desde el punto de vista jurídico, que el partido podrá expulsar de su seno a un miembro indisciplinado, podrá separarlo de sus cargos; incluso el grupo parlamentario podrá separarlo y sustituirlo en los cargos parlamentarios que ostentara en representación suya. Todo esto no afecta sino a la relación interna entre el partido y un militante. Pero lo 
que no podrá hacer es multar al diputado, como se hace, ni mucho menos exigirle una dimisión sin fecha para presentarla el grupo parlamentario en el momento en que más le acomode, como también se hace.

No digo yo que tales supuestos pudieran llevar a declarar inconstitucional a un partido por violar la Constitución. Al menos no debería ser así en un primer momento. Pero éstas son unas actuaciones antijurídicas (la calificación que hace Pérez Serrano de «prácticas abusivas» me parece excesivamente benévola) y, como tales, merecedoras de sanción. Lo que sucede es que ni los reglamentos parlamentarios ni las leyes ordinarias sobre partidos se encaran con este problema, habiendo en ello una grave laguna que cada vez es más urgente colmar.

A los partidos, en caso de indisciplina, no les cabe en la actualidad más que expulsarlo del partido, no presentar de nuevo su candidatura y procurar seleccionar mejor a sus candidatos en otra ocasión, y no por mero oportunismo, que ahí es donde suele radicar gran parte del problema.

En la IV República francesa llegó a tanto el abuso de las dimisiones sin fecha que la Asamblea Nacional se vio precisada a rechazar algunas. Y ésta es la postura adoptada en el Parlamento italiano, donde basta una declaración del interesado de querer mantener el escaño para que valga su voluntad actual y no una dimisión redactada no se sabe cuándo. Lo que ocurre es que estas declaraciones individuales son muy raras, pero en España han proliferado durante nuestra poco dilatada vida parlamentaria, sin que ninguno de los diputados afectados se haya visto privado de su escaño. Todo ello evidencia la tesis jurídica que vengo sosteniendo: la titularidad individual de los escaños y el carácter metamente interno de la relación entre el partido y un militante suyo, sea éste o no diputado. Por eso las «multas» a que antes hice referencia no entrañan para el diputado una obligación jurídica en sentido estricto, sino todo lo más una forma de las denominadas por la doctrina «obligaciones naturales», acaso una obligación ética. En rigor, estamos ante un crédito de satisfacción voluntaria, no cabiéndole al partido ninguna acción judicial en favor de su pretensión; podrá adoptar contra el «deudor» todas las medidas antes aludidas (expulsión del partido, etc.), pero nada más.

Así, pues, si el partido español UCD hubiera terminado solicitando de las Cortes Generales - como, según noticias aparecidas en la prensa, iba a hacerla declaración de indignidad de unos diputados indóciles, lo que les acarrearía la pérdida del escaño, si lo hubiera hecho, digo, las Cortes Generales tendrían que haber resuelto negativamente conforme a los artículos $23,66.1$ y 67.2 de la Constitución.

\subsection{Abandono del partido por parte del diputado}

Un problema muy parecido es el que plantea el diputado que abandona el partido con el que ganó el escaño. Cuando aludí a la titularidad de los escaños ya me hice eco de las dos posturas encontradas que existen y añadía mi tesis de la titularidad individual. Mi respuesta ahora, consiguientemente, es la de que el diputado no está obligado jurídicamente a dimitir. 
Estamos más bien ante un caso de obligación moral o, como dice Lucifredi, ante un problema de corrección constitucional; es decir, lo correcto sería que el diputado no se empeñara en conservar su escaño, pero no se pueden llevar las cosas más allá, porque, además de los inconvenientes jurídicos ya aludidos, no es impensable - ni inusual - que sea precisamente el partido el que se está separando de su programa electoral e incumpliendo sus compromisos con los electores. Pero dilucidar quién cumple mejor, si el diputado individual o el partido, es un problema de buenos y malos en el que el derecho no debe entrar, sino limitarse a conservar en su escaño a quien resultó elegido mientras no dimita.

$\mathrm{Y}$ no es aceptable la tesis de Kriele, quien, conforme al sistema electoral alemán, dictamina que el diputado debería perder el escaño si no fue elegido directamente, sino en la lista regional del partido. Aunque sea cierto que los así elegidos deben aún más su escaño al partido, ello no autoriza a diferenciar el estatuto de los diputados, haciendo a unos los representantes del pueblo y a otros los portavoces de los partidos.

\subsection{Escisión del partido}

Por lo demás, las desavenencias internas de un partido pueden llegar a ocasionar su escisión. Este es un caso que ilustra quizá como ningún otro la titularidad individual de los escaños y la permanencia de los diputados en los mismos, pues en caso contrario habría que dilucidar qué grupo de los resultantes es el auténtico continuador del partido originario. $\mathrm{Y}$ el pleito no tendría ninguna solución satisfactoria.

\subsection{Disolución de un partido por declaración de su inconstitucionalidad}

Seguramente pueden imaginarse muchos más supuestos jurídico-constitucionales en los que se ponga en juego el valor y la real vigencia del mandato representativo en el actual Estado de partidos. Pero acaso ninguno es tan sugestivo como el de la disolución de un partido como consecuencia de la declaración de su inconstitucionalidad. La pregunta es: ¿dicha disolución comporta la decadencia del mandato de los diputados que fueron elegidos en sus candidaturas?

Quienes contestan afirmativamente se apoyan en dos argumentos. Uno es la constitucionalización de la función mediadora de los partidos, lo que en nuestro supuesto quiere decir que esos diputados quedan sin nexo con el electorado y con el Parlamento. El otro argumento, de mayor entidad a mi juicio, consiste en que, como dice Rossano, la conservación de los escaños significatía dejar sin efecto, al menos sin efecto inmediato, la disolución del partido, pues éste perviviría, y nada menos que en el Parlamento, a través de sus diputados.

Quienes contestan negativamente se basan, a su vez, en el principio del 
mandato representativo y en que la calidad de diputado se funda en la elección y proviene, por tanto, del cuerpo electoral, motivo por el que el vínculo asociativo privado que exista entre el diputado y su partido no afecta al título jurídico de la elección. Por eso, dice Petta, la disolución del partido sólo comporta la de ese vínculo asociativo interno.

Otra tesis -a.mi juicio insostenible- es la de Henke, que dice que la declaración de inconstitucionalidad del partido determina la existencia de un vicio en el procedimiento electoral en el que ganó los escaños, vicio que justifica la invalidación parcial de los resultados. Me parece inaceptable no sólo por el principio de irretroactividad de las normas o resoluciones desfavorables, sino porque, de aceptar esta tesis, habría que anular todas las actuaciones parlamentarias en las que la partipación de dichos diputados fue decisiva en algún punto, bien en la existencia de quorum, bien en la votación final, etc. La anulación podría alcanzar a leyes, a ratificaciones de tratados e incluso a reformas constitucionales, todo lo cual nos parece inaceptable: la vida jurídica y política de un país no puede estar pendiendo de esa continua amenaza.

El Tribunal Constitucional Federal de Alemania declaró en dos ocasiones la inconstitucionalidad de un partido: del neonazi en 1952 y del comunista en 1956. Entre las dos fechas, la Ley Electoral de 1953, como la posterior de 1956, habían ya regulado el caso en el mismo sentido de la sentencia, es decir, desposeyendo de los escaños a los diputados del partido disuelto.

Dicha solución es discutible, pero más, mucho más, la argumentación de la sentencia, que en síntesis dice: hay una cierta contradicción entre los artículos 21 y 38 de la Ley Fundamental, cuya solución corresponde al juez, que valorará en cada caso cuál de los dos principios tiene mayor peso.

«Es difícil - dice P. Petta- imaginar un método interpretativo más incierto y más idóneo para permitir abusos y soluciones contradictorias.» En caso de difícil conciliación de dos preceptos de igual tango, la solución nunca puede ser prescindir unas veces de uno y otras de otro; la obligación del jurista — profesor, abogado, juez o tribunal- es buscar la solución que los contradiga lo menos posible y que esté más de acuerdo con el sistema político general del país.

Lo que ocurre, en realidad, es que estamos ante uno de esos supuestos cuyas posibles soluciones arreglan bien poco. A mí me parece que la solución jurídicamente más aceptable es la políticamente menos deseable: la permanencia de tales diputados en sus escaños. Ya sé que esto comporta el alargamiento de la vida de un partido disuelto, pero tiene una mayor apoyatura jurídica en el sistema vigente.

a) En primer lugar, porque no es contradictorio con la naturaleza de la justicia constitucional el que sus sentencias tengan unos efectos inmediatos (en nuestro caso, la disolución del partido) y otros aplazados (la pérdida de presencia parlamentaria, que no se consuma hasta el final de la legislatura).

b) En segundo lugar, porque lo que no puede hacer, según creo, un Tribunal Constitucional, sin estar habilitado para ello, es dejar sin efecto un acto del cuerpo electoral procesalmente correcto y firme, como lo fue en su día la elección de los diputados en cuestión. Las impugnaciones electorales siguen un procedimiento distinto. 
Si es una ley la que dispone el cese en estos casos, el problema que se plantea es precisamente el de la constitucionalidad de la misma, como, a mi juicio, cabe plantear con las mencionadas Leyes alemanas de 1953 y 1956. $\mathrm{Y}$ si es la propia Constitución la que incluye dicho precepto a la vez que la representación nacional y la prohibición de mandato, estamos ante un claro caso de flagrante contradicción, o de dos constituciones en una, que lo que exige es una revisión constitucional para restablecer la coherencia que debe tener todo texto legal.

La única solución plausible hoy por hoy para hacer decaer a los diputados de sus escaños es la de encausarlos individualmente, bien, si a ello hay lugar, en procedimiento criminal que pudiera llevarles, en su caso, a la pérdida temporal del derecho al ejercicio de cargo público, bien, en todo caso, en procedimiento de indignidad parlamentaria. Pero esto hay que hacerlo caso por caso, discriminando responsabilidades individuales, que no tienen necesariamente que ser iguales; es posible, por ejemplo, que alguno de esos diputados haya seguido una línea distinta a la de su partido en esas prácticas anticonstitucionales; es posible incluso que él mismo haya abandonado el partido por tal motivo y que sea uno de esos parlamentarios indisciplinados de que hemos hablado en las páginas anteriores. Y si entonces dijimos que no debían decaer de sus escaños, con mayor razón habría que decirlo ahora, cuando el motivo de la indisciplina reside en su acatamiento de la Constitución. Añadamos tan sólo que las protestas formales o los abandonos del partido en cuestión no son más que indicios, que no deben impedir el enjuiciamiento formal de responsabilidades, porque, de lo contrario, quedaría demasiado en franquía la puerta para «oportunos» abandonos que burlaran los mencionados procedimientos. Insisto: hay que juzgar caso por caso.

\section{* *.* $*$}

De todos modos no hace falta mucha imaginación para darse uno cuenta de que éste es uno de los supuestos más idóneos para haber.incorporado constitucionalmente la revocación: declarado inconstitucional un partido, quedaría disuelto y el número de electores que se determinara de las circunscripciones correspondientes podría iniciar la sustitución de los parlamentarios por los de otras organizaciones legales, sin que el partido disuelto pueda ya, por hipótesis, acudir a esta elección parcial.

Este es el punto al que queríamos llegar a través del discurso teórico que precede, que, si ha resultado un tanto extenso, espero que no haya sido tedioso. Ahora bien, dicha conclusión nos abre una interrogante no menos interesante: la de si es posible la conciliación de la revocación con el sistema constitucional vigente, la de si es posible insertarla en el Estado de partidos.

6. ¿CABE LA REVOCACION

EN EL ACTUAL MODELO DE REPRESENTACION?

Dice Norberto Bobbio en la forma expedita y brillante con que sabe polemizar: «Lejos de mí la idea de hacer del Estado representativo el alfa y la 
omega de la sapiencia política... Es un sistema mejor que los que le han precedido y que los que hasta ahora le han seguido... Pero hace aguas por todas partes, no porque sea un sistema representativo, sino porque no lo es bastante.»

Propuestas ha habido muchas para incrementar la representatividad del sistema, pero a nuestro estudio le interesa una especialmente: la introducción de la revocación. No decimos lo mismo de las instrucciones que se daban en la representación estamental por varios motivos: primero, porque esta práctica no es realmente posible con circunscripciones de electorado muy amplio (al menos, son inviables las instrucciones muy concretas y vinculantes de los electores), y segundo, porque las diversas agencias de articulación de intereses (asociaciones, ligas, grupos, sindicatos) ya las llevan a los partidos para que las incorporen a sus programas, y estos programas, como dijimos, ya hacen las veces de las instrucciones, aun con las diferencias que también apuntábamos. Nos centramos, por tanto, en la revocación.

El mismo Bobbio aduce que el principio de la revocación es muy discutible y que la fórmula leninista de «revocabilidad en cualquier momento de todos los representantes sin excepción ninguna» debe ser matizada si no se quiere caer en la arbitrariedad. Hace falta, añade, una muy cuidada articulación técnica que precise quién revoca, quién es el mandante y la posición de los partidos al respecto.

Esta reflexión tiene la virtud de reunir todos los elementos importantes del problema que suscitamos, al menos en su usual y polémica presentación. Son tres:

1. La aceptación leninista de la revocación y su vigencia en las actuales democracias populares, que no le ha hecho ningún favor a esta institución de cara a su posible incorporación a las democracias liberales.

2. La necesaria articulación técnica para evitar el fácil riesgo de la arbitrariedad.

3. La posición de los partidos al respecto.

Veámoslos brevemente.

\subsection{El mandato imperativo en el constitucionalismo soviético}

Marx, en La guerra civil en Francia, donde reflexiona sobre la Comuna de París, aludió al permanente control en que los representantes se encontraban por parte de sus electores. De ahí extrajo Lenin su idea sobre la necesidad del mandato imperativo. Y en el Decreto de 2-XII-1917, redactado por él mismo, afirma: «Toda institución electiva o asamblea representativa sólo puede ser considerada realmente democrática y representante efectiva de la voluntad popular si se reconoce y aplica el derecho de los electores de revocar a sus elegidos». El principio se incorporó al constitucionalismo de la URSS y posteriormente al de los países sometidos a su influencia.

Sin embargo, la evolución de la doctrina ha ido matizándolo. Pues, si bien no divergen los juristas demopopulares en que el modelo soviético de represen- 
tación es diferente del modelo burgués, sí lo hacen en cuanto a su preciso contenido.

Mientras que lo tradicional ha sido incluir en él la rendición de cuentas y la revocabilidad, se va abriendo paso una doctrina más alambicada, según la cual los lazos entre diputados y electores responden a un contrato tácito que no obliga al diputado a responder ante sus electores, sino ante el pueblo entero, lo que comienza a parecerse mucho a la representación burguesa de la nación entera. Esta es la posición de los soviéticos Toumanov y Kotov, del húngaro Kovacs y del búlgaro Spassov, entre otros.

El rumano Ion Vintu abunda en este sentido y ofrece la particularidad de escribir un trabajo precisamente sobre $L a$ democracia representativa en Rumania. Esto es digno de mención por dos motivos: de un lado, porque, frente al desprecio por las formas políticas burguesas, aquí se adopta el nombre de la más caracterizada de ellas: democracia representativa; de otro, porque no se considera incompatible con ésta la responsabilidad y la revocabilidad del diputado.

Hay, pues, un acercamiento doctrinal -sólo doctrinal, es cierto- al mandato representativo, sin llegar a él. Por eso E. Poppa, de la República Democrática Alemana, ha escrito: «La imagen de la posición y de la actividad del diputado socialista no tiene nada en común con las tipologías del pensamiento burgués sobre el Estado. Ni el 'mandato libre', que rechaza el ligamen de un deber jurídico de rendir cuentas a los electores y la revocabilidad, ni el 'mandato imperativo', que encierra a los diputados en una comunicación estéril y sin iniciativa con los mandatos de los electores y de grupos de electores... ninguno (de estos modelos) se corresponde con la concepción socialista de la sociedad y del Estado.»

Por lo que a nosotros nos interesa, la revocación de los elegidos reviste formas variadas en las diversas democracias populares:

- En Polonia y en Rumania se efectúa mediante escrutinio secreto y procedimiento similar al electoral.

- En Checoslovaquia, en Hungría y en la misma URSS, mediante votación a mano alzada en una asamblea de electores.

En cuanto a su eficacia, ha sido mayor en la representación local. Según datos que maneja Robert Charvin en su obra sobre los Estados socialistas europeos, cada año son revocados en la URSS varios cientos de diputados de soviets locales (concretamente, en 1967 fueron trescientos, que tampoco son tantos comparados con los muchos miles que suman en total). En Bulgaria, entre 1966 y 1971, fueron revocados 235 .

En cambio, es menos frecuente la revocación de diputados nacionales:

- Un solo caso en Checoslovaquia entre 1948 y 1963.

- Un solo caso en la República Democrática Alemana en el período 1965-1974.

- Diez diputados en la URSS entre 1958-1966.

Las razones de esta menor utilización de la revocación de diputados nacionales son varias:

a) Se suele presionar al diputado en entredicho para que dimita.

b) El procedimiento es muy complejo, como sucede en Polonia. 
c) Que no se haya articulado legalmente este instituto, como ocurrió en la URSS entre 1936 y 1958.

\subsection{Articulación técnica y posición de los partidos}

Ante todo creo que es conveniente aclarar que el ingrediente jacobinista del instituto es sólo anécdota y no categoría. Lo defendieron los jacobinos, sí, pero no por eso la revocación pertenece por esencia y exclusivamente al modelo jacobino de democracia directa y asamblearia, sino que cabe en cualquier sistema político. El hecho inconcuso de que sistemas de democracia directa como Suiza no lo incluyan y sí lo hagan sistemas a los que han sido ajenos el referéndum y la iniciativa popular (como son la URSS hasta 1977 y las democracias populares) nos ahorra más explicaciones.

Y no deja de ser curioso que nuestros sistemas políticos demoliberales hayan rechazado la revocación, que no atentaba a la denominada «lógica de las instituciones», $y$, sin embargo, hayan terminado dando entrada al referéndum y a la iniciativa popular, que sí contradicen abiertamente el principio originario de que la nación no puede querer sino a través de sus representantes, como contradicen igualmente la plenitud de poderes de éstos, sobre todo el referéndum abrogatorio.

En fin, como hemos dicho, la revocación es una técnica adaptable a cualquier sistema político. El problema radica en hacerlo bien o mal; nada más, pero nada menos.

a) Naturalmente, no se trata de estar todos los días de revocaciones, como no todos los días hay iniciativa popular legislativa, ni referéndum, ni moción de censura.

a.1) De un lado, sería prudente poner ciertos requisitos que disuadieran del aventurismo, como, por ejemplo, un elevado porcentaje de firmas de los electores de la circunscripción para iniciar el procedimiento.

a.2) De otro lado, parece lógico que los partidos terminaran siendo los únicos que pudieran alcanzar esas firmas, de manera que su protagonismo no sufriría merma. Pero se lo pensarían mucho antes de dar un paso en falso en este terreno por el descrédito consiguiente y el refuerzo que proporcionarían al partido y al diputado impugnados y confirmados. Por eso, si los partidos no se prodigan en ello, es fácil imaginar que no se incoarían muchas revocaciones, y menos se consumarían.

b) Además, habría que poner este problema en relación con el sistema electoral.

b.1) En los sistemas mayoritarios uninominales debería articularse, en su caso, como una revocación constructiva, por emplear una terminología bastante consolidada; esto es, un solo procedimiento en el que la iniciativa lleve incorporada las candidaturas alternativas. En realidad se sustanciaría como una elección parcial para un puesto que aún no está vacante y que no lo estará nunca porque la sustitución será automática.

b.2) En el sistema de mayorías con representación minoritaria la revocación constructiva no es aconsejable, pues sería una invitación al partido o coali- 
ción mayoritaria para hacerse con todos los escaños de la circunscripción ${ }^{1}$. La solución más idónea sería la ocupación de la vacante por el siguiente candidato en votos de la misma fuerza política, a quien se supone que, en su caso, habrían ido a parar en mayor cantidad los votos del revocado.

Y si la elección se hace por listas, debería ocupar el escaño el candidato siguiente en la lista del revocado.

b.3) En el sistema proporcional de listas también sería esta última la solución más adecuada.

c) Acaso los ámbitos más apropiados para iniciar la práctica de la revocación sean la representación local y la sindical. En la segunda viene siendo reclamada, en España, desde hace años. $Y$ en la representación local se ha introducido, pero tan deficientemente que más contribuirá al descrédito de esta institución que a su consolidación futura.

Digo esto porque el artículo 11 del Decreto-ley sobre Elecciones Municipales de 1978 establece que los concejales cesarán en su cargo si dejan de pertenecer al partido en cuya candidatura resultaron elegidos. Aunque la intención del precepto es la de mantener al representante local en la fidelidad a unos compromisos electorales, el procedimiento arbitrado es inadecuado y deja al representante definitivamente preso del partido, indefenso frente a él y sin posibilidad de acudir a la suprema instancia del cuerpo electoral. De este modo se introduce el mandato imperativo en su forma menos democrática, pues el mandante que instruye y revoca es el partido y no el electorado. Así, justamente así, es como no debe hacerse.

El triste episodio suscrito recientemente por el Partido Comunista de España en el Ayuntamiento de Madrid (expulsión del partido y consiguiente revocación de varios concejales, más la expulsión de los candidatos de la lista electoral que venían llamados a la sustitución, para poder llevar a la concejalía a sus militantes más dóciles), así como los ofrecidos, con menor espectacularidad, por el Partido Socialista de Andalucía en el Ayuntamiento de Granada y por el Partido Socialista Obrero Español en el de Madrid (cese de un teniente de alcalde por haber acusado de cohecho a unos compañeros de partido y de corporación, sin esperar a que la Administración de Justicia se pronuncie sobre dicha acusación), acontecimientos como éstos, repito, podrían disuadir de la conveniencia de introducir la revocación en el sistema político vigente. Hágase lo que se quiera de esto último, pero no por tales argumentos, que únicamente son objeción válida contra la deficiente regulación actual, no contra la institución misma.

${ }^{1}$ Así se ha podido apreciar durante nuestras dos. legislaturas democráticas en las elecciones parciales al Senado habidas en Asturias, Alicante, Almería y Sevilla. Añadamos que no ha habido intención dolosa por parte de nadie, y menos revocación de los senadores, sino que las vacantes lo fueron por muerte o por dimisión. En dichas elecciones parciales los escaños fueron ganados por el Partido Socialista Obrero Español, aunque algunos de ellos habían sido obtenidos por otro partido en las generales gracias al sistema de representación minoritaria. He aquí una grave disfuncionalidad de nuestro sistema electoral al Senado. 


\section{SUMARIA REFERENCIA BIBLIOGRAFICA}

P. Birnbaum, F. Hamon y M. Troper, Réinventer le Parlement, París, 1977.

N. Bobbio, ¿Qué socialismo?, ed. castellana, Barcelona, 1977.

F. de Carreras y J. M. Vallés, Las elecciones, Barcelona, 1977.

$\mathrm{R}$. Charvin, Les États socialistes européens, Toulouse (imp.), 1975.

M. Fraga, Legitimidad y representación, Barcelona, 1973.

H. Kelsen, Esencia y valor de la democracia, ed. castellana, Barcelona, 1977.

F. Leoni, Partidos políticos y grupos parlamentarios en Italia, en «Revista de Estudios Políticos», núm. 186, noviembre-diciembre, 1972.

L. Libertini, ¿Qué Parlamento?, ed. castellana, Barcelona, 1980.

P. Lucas Verdú, Curso de Derecho Político, vol. II, Madrid, 1974.

A. Manzella, Il Parlamento, Bolonia, 1977.

P. Petta, Gruppi parlamentari i partiti politici, en «Rivista italiana per le Scienze Giuridiche», 1970.

C. Rossano, Partiti e Parlamento nello Stato contemporaneo, Nápoles, 1972.

L. Sánchez Agesta, La participación en la vida pública a través del proceso representativo, en «Democracia y responsabilidad», Madrid, 1968.

C. Schmitt, Teoría de la Constitución, ed. castellana, Madrid, s. $f$.

A. Torres del Moral, Democracia y representación en los orígenes del Estado constitucional, en «Revista de Estudios Políticos», núm. 203, septiembre-octubre, 1975.

- Los grupos parlamentarios, en «Revista de Derecho Político», núm. 9, Madrid, 1981.

- Composición del Congreso de los Diputados, en «Revista de la Facultad de Derecho de la Universidad Complutense», núm. 58, Madrid, 1980. 